\title{
PERANCANGAN DAN PEMBUATAN SISTEM INFORMASI PERSETUJUAN PERBAIKAN DAN PERGANTIAN ALAT KOMPUTER BERBASIS WEB (Studi Kasus pada PT. Lautan Teduh Interniaga)
}

\author{
Eko Bambang Adithya, R. Arum Setia Priadi, Herlinawati \\ Jurusan Teknik Elektro Fakultas Teknik \\ Universitas Lampung \\ Jl. Prof. Soemantri Brojonegoro No.1 Bandar Lampung 35145 \\ ebaadithya@gmail.com;rasp@unila.ac.id
}

\begin{abstract}
Abstrak
Sistem Informasi Persetujuan Perbaikan dan Pergantian alat Komputer Berbasis Web merupakan sebuah aplikasi berbasis web yang dibangun untuk membantu dealer dalam mengajukan permohonan perbaikan dan pergantian alat komputer ke dealer utama. Dengan aplikasi ini dealer tidak perlu melakukan permohonan persetujuan perbaikan dan pergantian alat komputer dengan cara manual. Aplikasi ini dibangun dari bahasa pemrograman PHP dengan metode pemrograman berorientasi objek dengan metode pengembangan Rational Unified Process. Pada tahap analisa peneliti menggunakan $U M L$ sebagai bahasa pemodelan. Aplikasi persetujuan perbaikan dan pergantian alat komputer ini bisa dijalankan di berbagai macam browser seperti Modzilla Firefox, Google Chrome, dan Internet Explorer. Pada tahap pengujian dilakukan uji fungsionalitas dengan menggunakan software Selenium IDE dan uji non-fungsionalitas menggunakan metode black box testing tanpa menggunakan software. Kelebihan pengujian dengan menggunakan software ialah, dapat meringankan proses pengujian dengan tidak memerlukan SDM yang banyak. Hasil pengujian menunjukkan aplikasi yang dibangun berjalan dengan lancar dan memiliki waktu proses yang baik.
\end{abstract}

Kata kunci : Manual, Rational Unified Process, UML, PHP, White Box Testing, Black Box Testing, Selenium IDE

Abstract

Information System Design and Development of Computer Equipment Repair and Turn Agreement Based Web is a web based application built to assist dealers in applying proposal for the repair and replacement of computer tools to primary dealers. With this application the dealer does not need to request approval of repair and replacement of computer tools manually. This application is built on the PHP programming language with object-oriented programming methods with methods of developing the Rational Unified Process. At this stage of the analysis the researcher using UML as the modeling language. Application approval appliance repair and replacement computer can run on a variety of browsers such as Mozilla Firefox, Google Chrome, and Internet Explorer. In the testing phase to test the functionality using white box testing methods with Selenium IDE software and non - fungsionalitas testing using black box testing methods without using software. The advantages of using software testing is, can ease the testing process and does not require a lot of human resources. The test results showed an application built to run smoothly and have a good time processes.

Keywords : Manual, Rational Unified Process, UML, PHP, White Box Testing, Black Box Testing, Selenium IDE 


\section{PENDAHULUAN}

PT. Lautan Teduh Interniaga merupakan dealer utama sepeda motor Yamaha Lampung. Perusahaan ini merupakan sebuah perusahaan yang bergerak di bidang penjualan otomotif (kendaraan roda dua) skala nasional, ia memiliki banyak cabang atau dealer yang tersebar di berbagai wilayah di Lampung. Selama ini setiap dealer yang akan mengajukan permohonan perbaikan dan pergantian alat komputer kepada dealer utama harus melalui proses yang cukup lama dan rumit, karena semua proses masih manual menggunakan kertas sehingga tidak efisien dan menghabiskan banyak waktu. Oleh karena itu dirasa perlu dibuatkan suatu sistem informasi untuk membantu setiap dealer yang akan mengajukan permohonan perbaikan dan pergantian alat komputer ke dealer utama tanpa melalui proses yang panjang dan rumit sehingga dapat menghemat waktu.

Sistem informasi ini diharapkan dapat membantu kinerja setiap dealer karena tidak perlu lagi melalui proses yang panjang dan rumit untuk melakukan permohonan perbaikan dan pergantian alat komputer yang rusak ke dealer utama, dengan sistem ini pula dealer utama diharapkan dapat dengan cepat mengetahui setiap permohonan yang muncul dan dapat meresponnya dengan cepat.

\section{TINJAUAN PUSTAKA}

\subsection{Pengertian Sistem Informasi}

Sistem informasi merupakan bagian yang penting pada manajemen perusahaan dalam mengambil keputusan dan sumber informasi berupa data yang telah diproses dan menghasilkan data baru yang lebih berarti dan berguna bagi penggunanya. Berdasarkan definisi dari beberapa ahli pada dasarnya sistem informasi memiliki kesamaan, yaitu untuk mencapai tujuan perusahaan dari sistem yang diberlakukan. Dari beragam definisi, dapat disimpulkan bahwa sistem informasi mencakup sejumlah komponen (manusia, komputer, teknologi informasi, dan prosedur kerja), proses (data menjadi informasi), dan sasaran atau tujuan.

Sistem informasi adalah data yang dikumpulkan, dikelompokan dan diolah sedemikian rupa sehingga menjadi sebuah kesatuan informasi yang saling terkait dan saling mendukung sehingga menjadi suatu informasi yang berharga bagi yang menerimanya ${ }^{[1]}$

\subsection{Rational unified process}

Metode yang digunakan dalam pengembangan sistem adalah metode RUP (Rational Unifed Process). Pengembangan sistem dengan metode RUP dilakukan secara iteratif (berulang) dan incremental (bertahap dengan progress menaik). RUP memiliki empat fase yang dilakukan secara berurutan dan iteratif di mana setiap iterasi dapat digunakan untuk memperbaiki iterasi berikutnya.

1. Inception

Pada tahap ini dilakukan pemodelan proses bisnis yang dibutuhkan dan mendefinisikan kebutuhan user yang akan dibuat.

\section{Elaboration}

Tahap ini lebih difokuskan pada perencanaan arsitektur sistem, dan mendeteksi apakah arsitektur yang dibuat diinginkan, serta mendeteksi resiko yang mungkin terjadi dari arsitektur yang buat. Tahap ini lebih pada analisis dan desain sistem serta imp-lementasi sistem yang fokus pada purwarupa sistem (prototype).

\section{Construction}

Pada tahap ini dilakukan pengembangan komponen dan fitur-fitur sistem. Tahap ini lebih pada implementasi dan pengujian sistem yang fokus pada imple-mentasi perangkat lunak pada kode program.

\section{Transition}

Pada tahap ini dilakukan deployment atau instalasi sistem agar dapat dimengerti oleh user. Aktifitas pada tahap ini termasuk pada pelatihan user, pemeliha-raan, dan pengujian sistem apakah sudah memenuhi harapan sser. $^{[2]}$

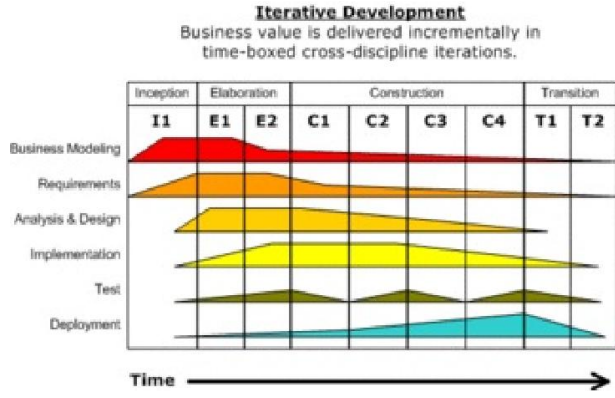

Sumber : http://en.wikipedia.org Gambar 1. Metode RUP 


\subsection{Sistem Basis Data}

Basis data terdiri atas 2 kata, yaitu basis dan data. Basis dapat diartikan sebagai markas atau gudang, tempat bersarang / berkumpul. Sedangkan data adalah representasi fakta dunia nyata yang mewakili suatu objek seperti manusia (pegawai, siswa, pembeli, pelanggan), barang, hewan, peristiwa, konsep, keadaan, dan sebagainya, yang direkam dalam bentuk angka, huruf, simbol, teks, gambar, bunyi, atau kombinasinya. Prinsip kerja basis data adalah pengaturan data. Tujuan basis data adalah kecepatan dan kemudahan dalam pengambilan kembali data. ${ }^{[4]}$

\subsection{UML(Unified Modeling Language)}

Pada perkembangan teknik pemrograman berorientasi objek, muncullah sebuah standarisasi bahasa pemodelan untuk pembangunan perangkat lunak yang dibangun dengan menggunakan teknik pemrograman berorientasi objek, yaitu Unified Modeling Language (UML). UML muncul karena adanya kebutuhan pemodelan visual untuk menspesifikasikan, menggambarkan, membangun, dan dokumentasi dari sistem perangkat lunak. UML merupakan bahasa visual untuk pemodelan dan komunikasi mengenai sebuah sistem dengan menggunakan diagram. UML terdiri dari bermacam-macam diagram yang digunakan untuk permodelan pada saat pengembangan sistem mulai dari tahap analisi sampai implementasi. Pada saat melakukan desain sistem, tidak harus semua diagram pada UML diimplementasikan akan tetapi UML merupakan diagram yang saling terkait oleh karena itu perlu adanya kekonsistenan rancangan diagram yang satu dengan lainnya. ${ }^{[3]}$

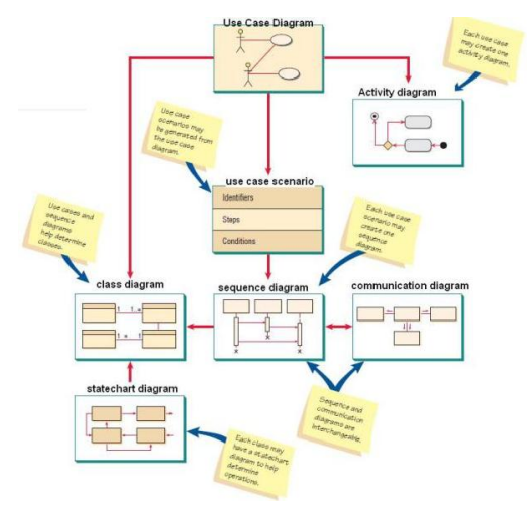

Gambar 2. Diagram UML

\subsection{PHP}

PHP (Hypertext Preprocessor) merupakan perangkat lunak open source yang diatur dalam aturan general purpose licences (GPL). Pemrograman PHP sangat cocok dikembangkan dalam lingkungan web, karena PHP bisa dilekatkan pada script HTML atau sebaliknya. PHP dikhususkan untuk pengembangan web dinamis. Maksudnya, PHP mampu menghasilkan website yang secara terus menerus hasilnya bisa berubah-ubah sesuai dengan pola yang diberikan, dan bergantung pada permintaan client browser.

\subsection{MySQL}

MySQL merupakan database yang menghubungkan script PHP dengan menggunakan perintah query dan escape character yang sama dengan PHP. MySQL mempunyai tampilan client yang mempermudah user dalam mengakses database dengan kata sandi untuk mengijinkan proses yang akan dilakukan. Kelebihan dari MySQL dapat melakukan transaksi dengan mudah dan efisien serta mampu menangani jutaan user dalam waktu yang bersamaan. ${ }^{[4]}$

\subsection{Xampp}

XAMPP adalah perangkat lunak bebas yang merupakan kompilasi dari beberapa program, yang mendukung banyak sistem operasi. Fungsinya adalah sebagai server yang berdiri sendiri, yang terdiri atas program Apache HTTP Server, MySQL database, dan interpreter untuk bahasa pemrograman PHP dan Perl. Xampp dapat diunduh http://www.apachefriends.org/en/xampp.html

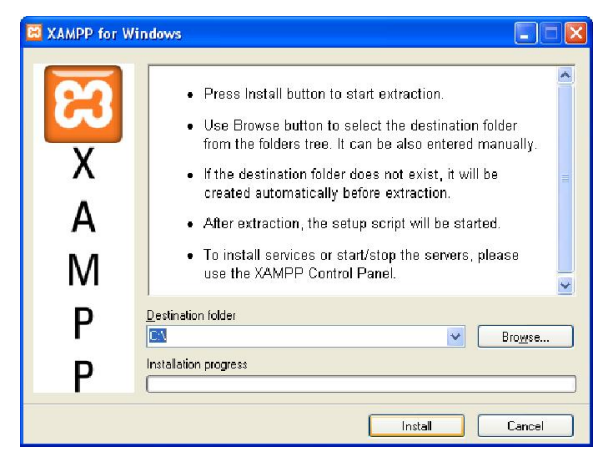

Gambar 3. Tampilan instalasi xampp 


\subsection{JUDE Community}

JUDE Community merupakan salah satu program bantu yang dapat digunakan untuk menggambar diagram-diagram UML. Program ini adalah aplikasi berbasis JAVA, aplikasi ini dapat diunggah di http://jude.change-vision.com

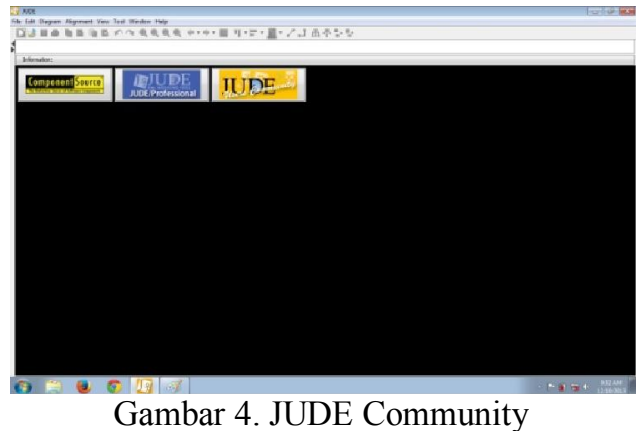

\subsection{Selenium IDE}

Selenium IDE adalah sebuah Integrated Development Environment (IDE) lengkap untuk pengujian menggunakan Selenium. Selenium IDE diimplementasikan sebagai ekstensi Firefox, dan dapat merekam, mengubah, dan men-debug suatu pengujian. Untuk memasang Selenium IDE pada Mozilla Firefox dapat dengan mengunjungi http://seleniumhq.org/download

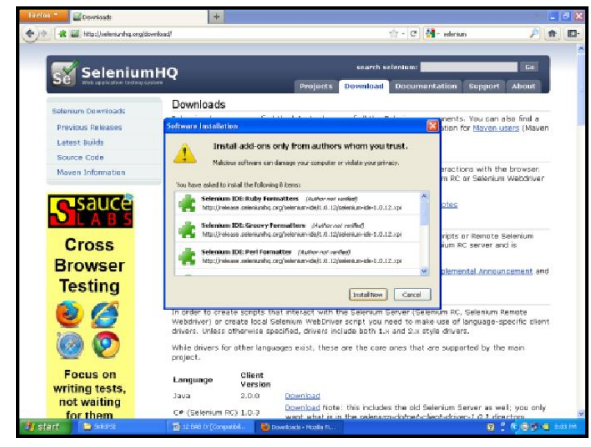

Gambar 5. Tampilan instalasi Selenium IDE

\section{METODE PENELITIAN}

Dalam menyelesaikan tugas akhir ini, digunakan RUP sebagai metode perancangan perangkat lunak dam UML sebagai notasi pemodelannya.

\section{Business Modelling}

Spesifikasi Kebutuhan Perangkat Lunak atau Software Requirement Specification (SRS) adalah merupakan pernyataan resmi dari apa yang dibutuhkan dari pembangun sistem. SRS Sistem Informasi Persetujuan Perbaikan dan Pergantian alat Komputer Berbasis Web adalah sebagai berikut:

a. Menyediakan form login untuk otorisasi (SRS- LAUTAN TEDUH -01).

b. Menyediakan halaman panduan pengiriman dan pergantian password (SRS- LAUTAN TEDUH -02).

c. Menyediakan form input data permohonan bagi dealer (SRS- LAUTAN TEDUH -03).

d. Menyediakan form rekomendasi permohonan bagi IT MD SHOP dan IT MAIN DEALER (SRS- LAUTAN TEDUH -04).

e. Menyediakan form Respon permohonan, lihat permohonan, dan cari permohonan (SRS- LAUTAN TEDUH 05).

f. Menyediakan menu logout agar dapat keluar dari sistem dengan aman (SRSLAUTAN TEDUH -06).

g. Menyediakan form list permohonan bagi dealer untuk mengetahui permohonan sudah direspon atau belum oleh SM, GM MD SHOP dan GM FA (SRS- LAUTAN TEDUH -07) .

h. Menyediakan menu lihat detail permohonan (SRS-LAUTAN TEDUH 08).

i. Menyediakan menu cetak permohonan hanya untuk dealer dan IT MD (SRSLAUTAN TEDUH -09).

j. Menyediakan fitur nota sebagai bukti permohonan telah disetujui (SRSLAUTAN TEDUH -10).

\section{Requirements}

a. User Requirement

1. Dealer, yaitu pihak pertama yang mengirimkan form permohonan baik form permohonan perbaikan atau pergantian. 
2. IT MD SHOP, yaitu IT Main Dealer Shop adalah pihak pertama yang menerima laporan permohonan dan bertugas untuk memberikan rekomendasi sehingga permohonan dapat diteruskan ke SM.

3. SM, yaitu Sales Manager adalah pihak yang akan merespon permohonan yang telah diberikan rekomendasi oleh IT MD SHOP, Sales Manager mempunyai dua pilihan yaitu menyetujui atau menolak permohonan, jika permohonan disetujui maka permohonan akan diteruskan ke GM MD SHOP.

4. GM MD SHOP, yaitu Grand Manager Main Dealer Shop adalah salah satu pihak yang akan merespon permohonan, GM MD SHOP mempunyai dua pilihan yaitu menyetujui atau menolak permohonan, jika permohonan disetujui maka permohonan akan diteruskan ke IT MD.

5. IT MD, yaitu IT Main Dealer adalah pihak yang akan memberikan rekomendasi terhadap permohonan agar bisa diteruskan ke GM FA, dia juga berperan sebagai admin yang bertanggung jawab terhadap web.

6. GM FA, yaitu Grand Manager Finance Accounting adalah pihak terakhir yang menerima permohonan, dan juga menjadi pihak yang akan memberikan keputusan akhir terhadap permohonan apakah akan disetujui atau ditolak.

\section{b. System Requirement}

Perangkat yang dibutuhkan oleh sistem informasi persetujuan perbaikan dan pergantian alat komputer ini dapat digambarkan dengan jelas dalam gambar di bawah ini:

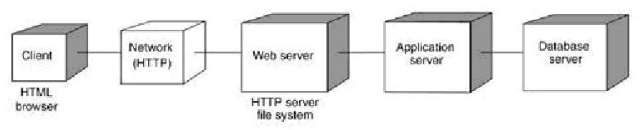

Gambar 6. Bagan Perangkat Sistem
Bagan perangkat sistem di atas menunjukkan node inti: client, network, Web Server, application server, dan database server. Masing-masing node server ini dapat benar-benar terpisah secara fisik/mesin atau dapat juga berupa satu mesin yang sama. Sistem informasi ini akan menggunakan bahasa PHP dan menggunakan basis data MySQL. Sehingga pada server harus berjalan service PHP dan MySQL. Pada client atau user diperlukan HTML browser untuk mengakses, misalnya Internet Explorer, Mozilla Firefox, atau Google Chrome.

\section{Analysis and Design}

a. Diagram Alir Sistem

Gambar dibawah ini menggambarkan bagaimana data mengalir pada Sistem :

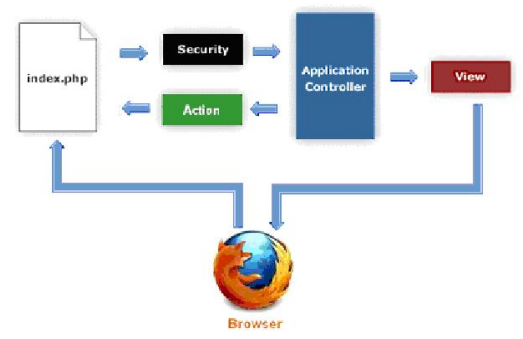

Gambar 7. Diagram Alir Sistem

b. Diagram use case

Sebelum membuat diagram use case, terlebih dahulu diidentifikasi daftar aktor atau user yang terlibat dan use case yang digunakan. Tabel daftar aktor dan tabel daftar use case dapat dilihat pada tabel di bawah ini

Tabel 1. Definisi use case

\begin{tabular}{|l|l|l|}
\hline No & \multicolumn{1}{|c|}{ Definisi Use Case } & \multicolumn{1}{|c|}{ Deskripsi } \\
\hline 1 & Login & $\begin{array}{l}\text { Autorisasi bagi semua aktor untuk bisa masulk } \\
\text { kedalam sistem. }\end{array}$ \\
\hline 2 & Kirim Permohonan & $\begin{array}{l}\text { Mengirim permohonan perbaikan atau } \\
\text { pernbelian yang harny dapat dilakukan oleh } \\
\text { dealer. }\end{array}$ \\
\hline 3 & Lihat permohonan & Melihat list data permohonan. \\
\hline 4 & Cari permohonan & $\begin{array}{l}\text { Mencari permohonan yang pernah dikirim oleh } \\
\text { dealer. }\end{array}$ \\
\hline 5 & $\begin{array}{l}\text { Input data inventaris } \\
\text { barang baru }\end{array}$ & Memasukan kode barang. \\
\hline 6 & Melihat panduan sistem & $\begin{array}{l}\text { Melihat langkah langkah kirim permohonan, } \\
\text { tata cara input data barang baru, dan mengganti } \\
\text { password. }\end{array}$ \\
\hline 7 & Ganti password & Mengganti password untuk masuk ke sistem. \\
\hline 8 & Logout & Keluar dari sistem dengan aman. \\
\hline 9 & $\begin{array}{l}\text { Rekomendasi } \\
\text { permohonan }\end{array}$ & $\begin{array}{l}\text { Merekomendasi permohonan agar bisa } \\
\text { dilanjutkan. }\end{array}$ \\
\hline 10 & Respon permohonan & $\begin{array}{l}\text { Merespon permohonan dengan memberi } \\
\text { persetujuan atau menolakmya. }\end{array}$ \\
\hline
\end{tabular}


Tabel 2. Daftar pengguna pada sistem

\begin{tabular}{|c|c|}
\hline Daftar User (Role) & Use Case \\
\hline Dealer & $\begin{array}{ll}1 & : \text { Login } \\
2 & : \text { Kirim permohonan } \\
3 & : \text { Lihat permohonan } \\
4 & : \text { Cari permohonan } \\
5 & : \text { Input data inventaris barang baru } \\
6 & : \text { Lihat panduan } \\
7 & : \text { Ganti password } \\
8 & : \text { Logouf }\end{array}$ \\
\hline IT MD Shop & $\begin{array}{ll}1 & : \text { Login } \\
2 & : \text { Rekomendasi permohonan } \\
3 & : \text { Lihat permohonan } \\
4 & : \text { Cari permohonan } \\
5 & : \text { Lihat panduan } \\
6 & : \text { Ganti password } \\
7 & \text { : Logout }\end{array}$ \\
\hline Sales Manager & $\begin{array}{ll}1 & : \text { Login } \\
2 & : \text { Respon permohonan } \\
3 & : \text { Lihat permohonan } \\
4 & : \text { Cari permohonan } \\
5 & : \text { Lihat panduan } \\
6 & : \text { Ganti password } \\
7 & : \text { Logout }\end{array}$ \\
\hline Sales Manager & $\begin{array}{ll}1 & : \text { Login } \\
2 & : \text { Respon permohonan } \\
3 & : \text { Lihat permohonan } \\
4 & : \text { Cari permohonan } \\
5 & : \text { Lihat panduan } \\
6 & : \text { Ganti password } \\
7 & : \text { Logout }\end{array}$ \\
\hline Grand Manager MD Shop & $\begin{array}{ll}1 & \text { : Login } \\
2 & \text { :Respon permohonan } \\
3 & : \text { Lihat permohonan } \\
4 & \text { Cari permohonan } \\
5 & \text { : ihat panduan ganti password } \\
6 & \text { Ganti password } \\
7 & \text { : Logout }\end{array}$ \\
\hline IT Main dealer & $\begin{array}{ll}\text { 1. } & \text { : Login } \\
\text { 2. } & \text { : Rekomendasi permohonan } \\
\text { 3. } & \text { : Lihat permohonan } \\
\text { 4. } & \text { Cari permohonan } \\
\text { 5. } & \text { : ihat panduan ganti password } \\
\text { 6. } & \text { : Ganti password } \\
\text { 7. } & \text { Logoult }\end{array}$ \\
\hline $\begin{array}{l}\text { Grand Manager Finance } \\
\text { Accoounting }\end{array}$ & $\begin{array}{ll}1 & \text { :Login } \\
2 & \text { Respon permohonan } \\
3 & \text { : Lihat permohonan } \\
4 & \text { Cari permohonan } \\
5 & \text { : Lihat panduan ganti password } \\
6 & \text { :Ganti password } \\
\end{array}$ \\
\hline
\end{tabular}

Berikut adalah diagram use case aktor-aktor yang terdapat pada Sistem, yaitu Dealer, IT Main Dealer Shop, Sales Manager, Grand Manager MD Shop, IT Main Dealer, dan Grand Manager Finance Accounting.

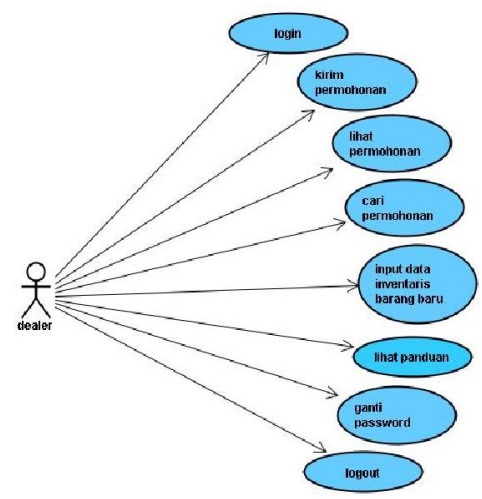

Gambar 9. Diagram use case aktor Dealer

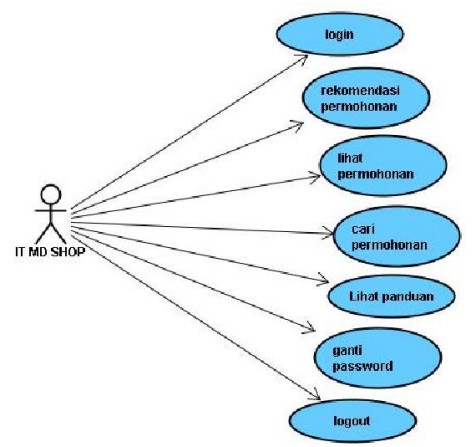

Gambar 10. Diagram use case IT Main Dealer Shop

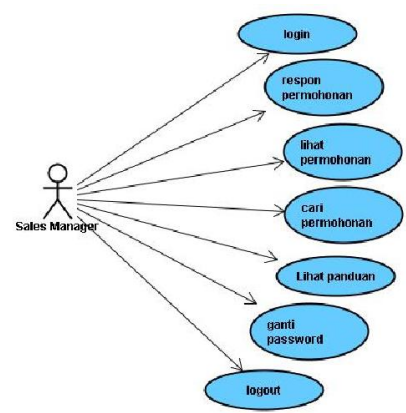

Gambar 11. Diagram use case aktor Sales Manager

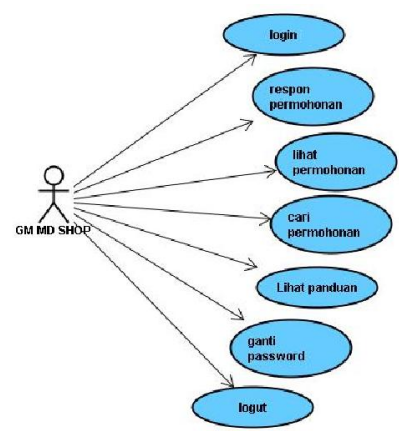

Gambar 12. Diagram use case aktor Grand Manager MD Shop

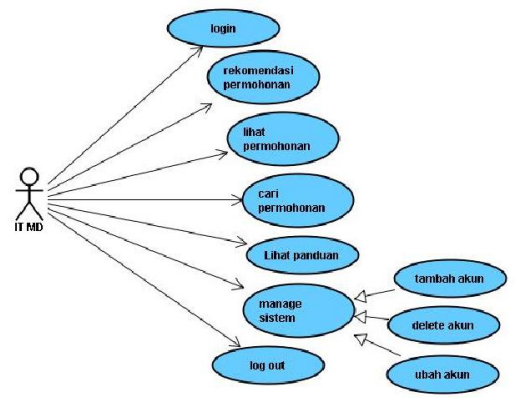

Gambar 13. Diagram use case aktor IT Main Dealer 


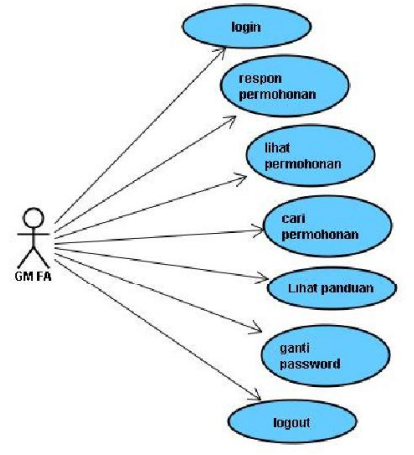

Gambar 14. Diagram use case aktor GMFA

\section{c. Rancangan logika prosedural sistem}

Rancangan logika prosedural pada sistem yang akan dibangun menggunakan sequence diagram dan activity diagram. Berikut gambar rancangan logika procedural dari sistem yang akan dibangun.

1. Logika prosedural use case login

Diagram berikut menggambarkan skenario dalam melakukan login ke dalam sistem oleh user yang telah memiliki hak akses, user yang dapat melakukan login adalah dealer.

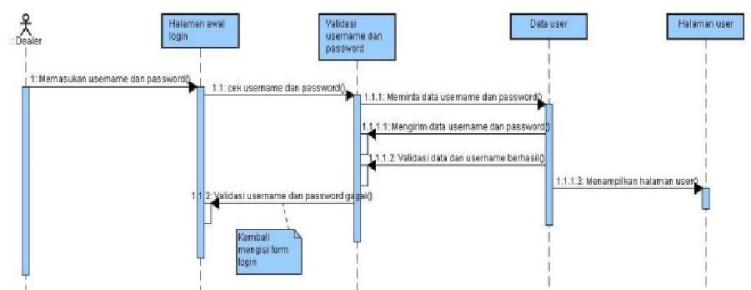

Gambar 14. Sequence diagram use case login untuk aktor dealer

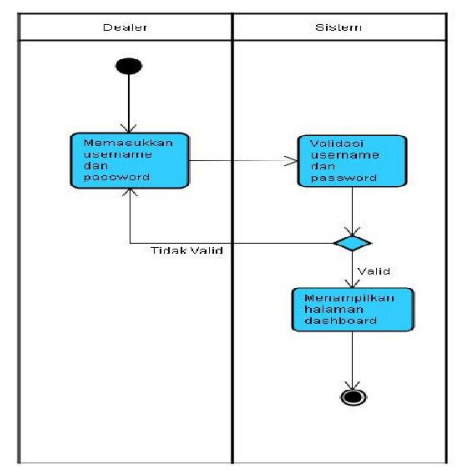

Gambar 15. Activity diagram use case login untuk aktor dealer
2. Logika prosedural use case kirim permohonan

Diagram berikut menggambarkan skenario dalam melakukan kirim permohonan, user yang dapat melakukan kirim permohonan adalah dealer.

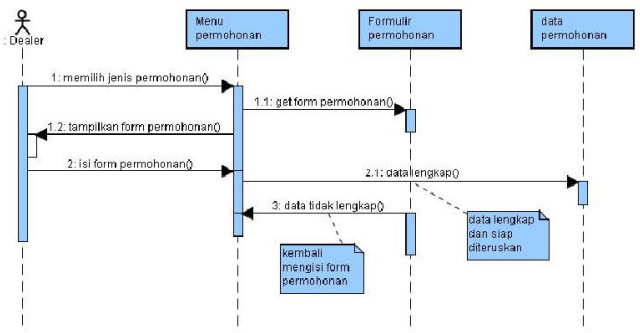

Gambar 16. Sequence diagram use case kirim permohonan

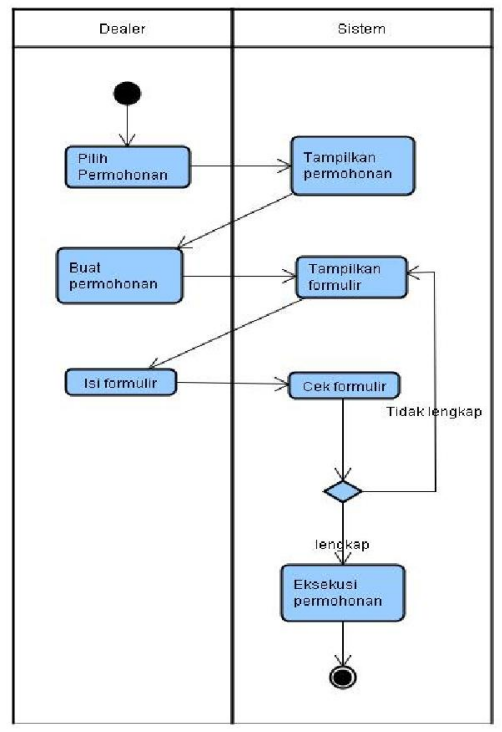

Gambar 17. Activity diagram use case kirim permohonan

\section{d. Rancangan Database}

Rancangan database dari sistem yang dibangun menggunakan analisis class dan class diagram. Di mana class diagram menjelaskan class yang ada pada sistem yang dibangun. Class diagram tersebut menggambarkan struktur statis dari sebuah sistem,. objek-objek yang dipakai, serta hubungan antar class yang ada. Berikut rancangan database sistem yang digambarkan dengan class diagram pada gambar di bawah. 


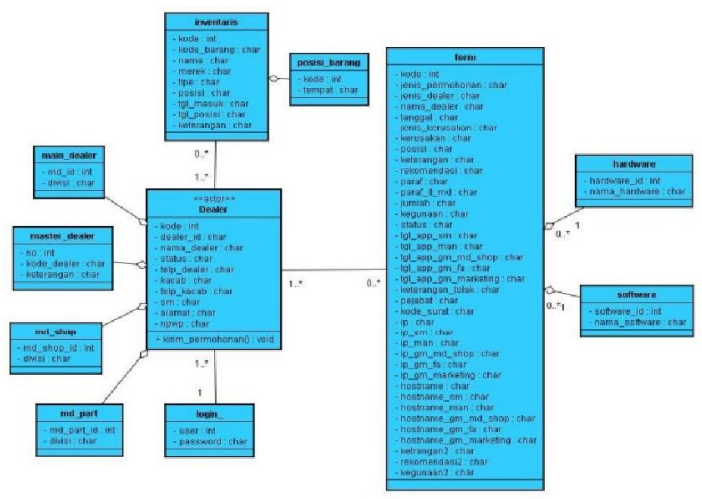

Gambar 18. Class diagram

\section{HASIL DAN PEMBAHASAN}

\section{A. Hasil}

Proses pembuatan Sistem Informasi Persetujuan Perbaikan dan Pergantian Alat Komputer Berbasis Web Studi Kasus pada PT. Lautan Teduh Interniaga dilakukan dengan metode pengembangan Rational Unified Process. Sistem informasi ini dikembangkan dengan bahasa PHP dengan teknik Pemrograman Berorientasi Objek. Pemodelan pada pengembangan sistem ini menggunakan $U M L$.

Dalam metode Rational Unified Process yang terbatas pada Core Process Workflows, perangkat lunak dikembangkan secara iterasi dengan enam jenis kegiatan yang harus dilakukan yaitu business modelling, requirements, analysis and design, implementation, testing dan deployment. Di mana dalam melakukan kegiatan-kegiatan tersebut terdapat empat fase yang harus dilalui yaitu fase permulaan, fase perluasan, fase konstruksi, dan fase transisi. Fase - fase tersebut menunjukkan waktu dilakukannya kegiatan iterasi.

\section{Implementasi antarmuka web}

1. Halaman login

Pada halaman utama terdapat halaman Login yang digunakan untuk akses masuk ke halaman aplikasi, dengan hak akses masing-masing user yaitu dealer, IT MD SHOP, SM, GM MD SHOP, IT MD, dan GM. Untuk dapat melakukan akses masuk ke halaman aplikasi, user harus memasukkan user id dan password pada kolom yang tersedia, kemudian mengklik tombol login.

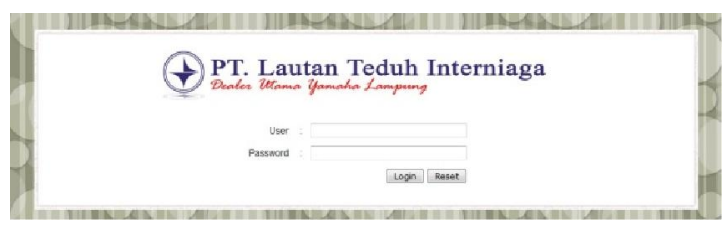

Gambar 19. Tampilan login

\section{Halaman home}

Halaman ini akan tampil setelah user melakukan login ke website.

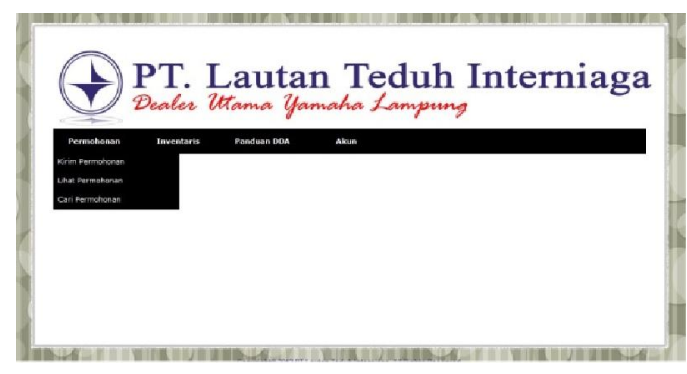

Gambar 20. Tampilan home

3. Halaman kirim permohonan

Halaman ini tersedia khusus untuk user dealer yang akan mengajukan permohonan.

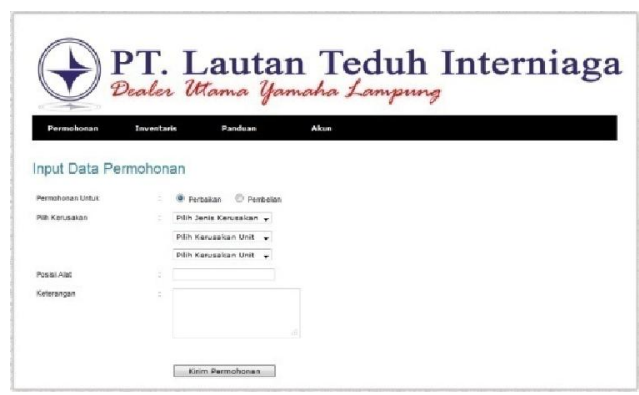

Gambar 21. Tampilan kirim permohonan

4. Tampilan lihat permohonan

Pada gambar di bawah dapat dilihat tanggal permohonan, jenis permohonan, kerusakan, dan dapat dilihat pula permohonan diterima atau ditolak oleh SM, GM MD SHOP dan GM FA berikut tanggalnya. Pada bagian sebelah kanan dapat dilihat icon untuk melihat detail permohonan atau mencetaknya 


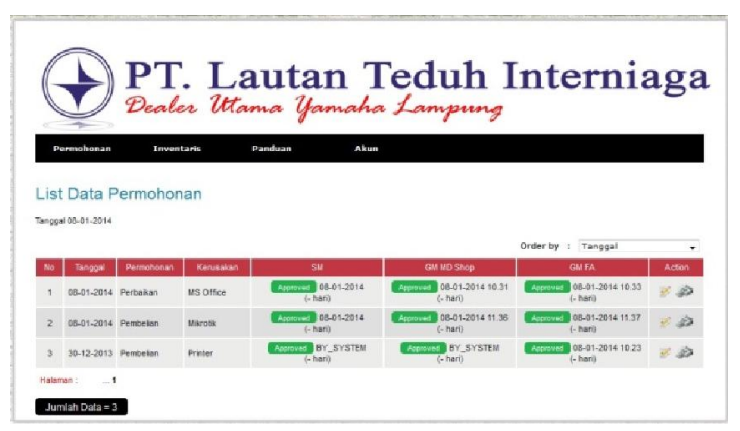

Gambar 22. Tampilan lihat permohonan

5. Tampilan cari permohonan

Pada gambar di bawah ini dapat terlihat data permohonan dapat dicari berdasarkan periode awal, periode akhir, dan urutan berdasarkan tanggal.

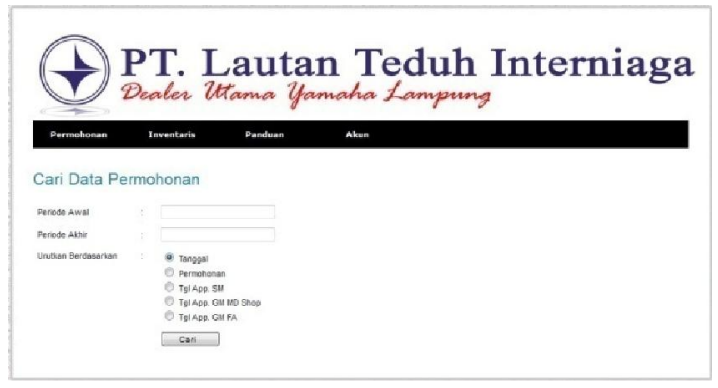

Gambar 23. Tampilan cari permohonan

6. Tampilan input kode barang

Pada gambar di bawah ini dapat dilihat menu memasukan kode barang untuk user dealer

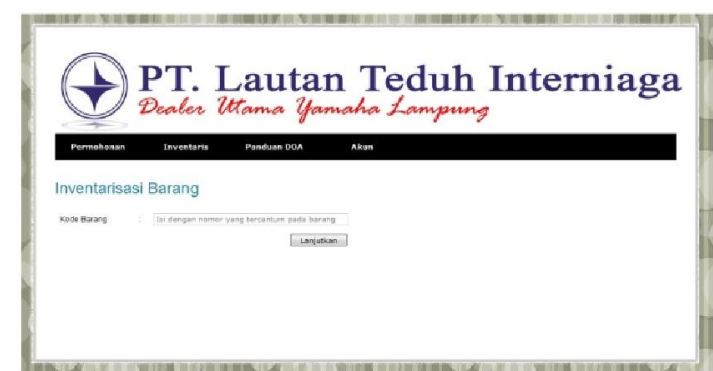

Gambar 24. Tampilan input data barang untuk user dealer

7. Tampilan input data invetaris user IT MD

Pada gambar di bawah ini dapat dilihat menu memasukan data inventaris untuk user IT MD

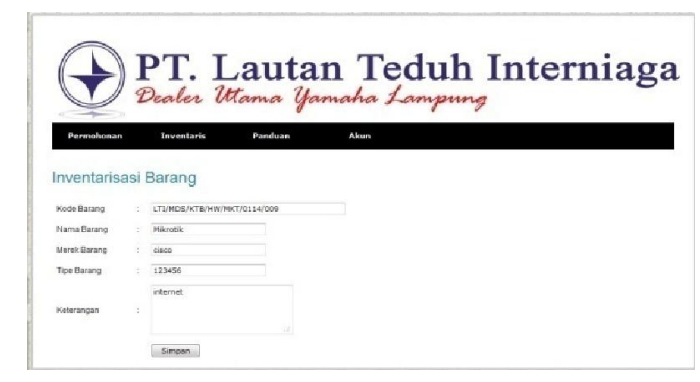

Gambar 25. Tampilan input data inventaris untuk user dealer

8. Tampilan menu rekomendasi

Pada gambar di bawah ini dapat dilihat tampilan menu rekomendasi untuk user IT MD SHOP maupun IT MD, dari gambar di atas dapat dilihat permohonan yang belum diberikan rekomendasi.

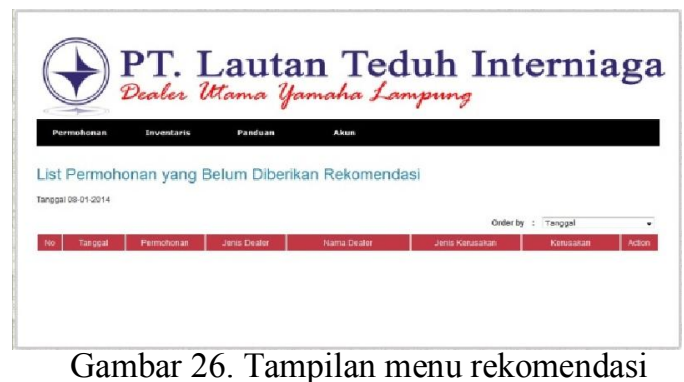

9. Tampilan menu respon

Gambar di bawah ini adalah tampilan menu respon permohonan untuk user SM, GM MD SHOP maupun GM FA, di halaman inilah setiap permohonan yang ada akan diberikan respon baik itu ditolak ataupun diterima.

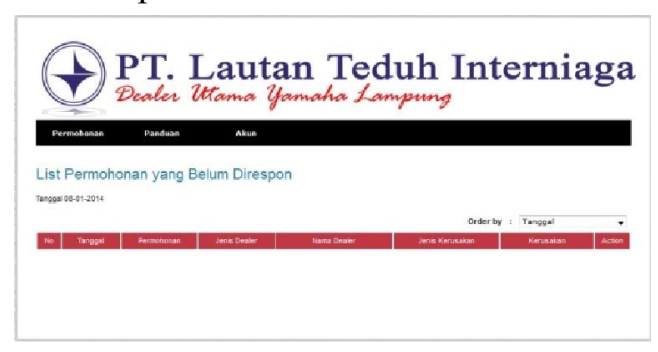

Gambar 27. Tampilan menu respon

10. Tampilan nota permohonan pembelian adalah tampilan nota permohonan pembelian. Setiap permohonan yang telah diberikan persetujuan oleh SM, GM MD SHOP dan GM FA akan diberikan sebuah bukti berupa nota yang hanya bisa dicetak oleh dealer 


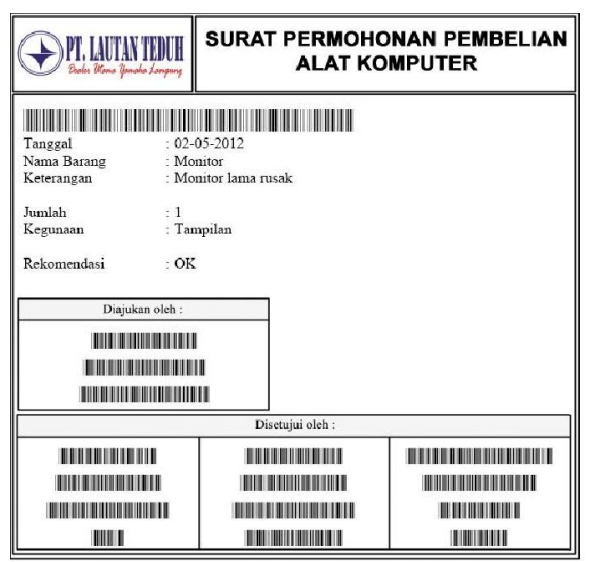

Gambar 28. Tampilan nota pembelian

11. Tampilan nota perbaikan

adalah tampilan nota permohonan perbaikan. Setiap permohonan yang telah diberikan persetujuan oleh SM, GM MD SHOP dan GM FA akan diberikan sebuah bukti berupa nota yang hanya bisa dicetak oleh dealer

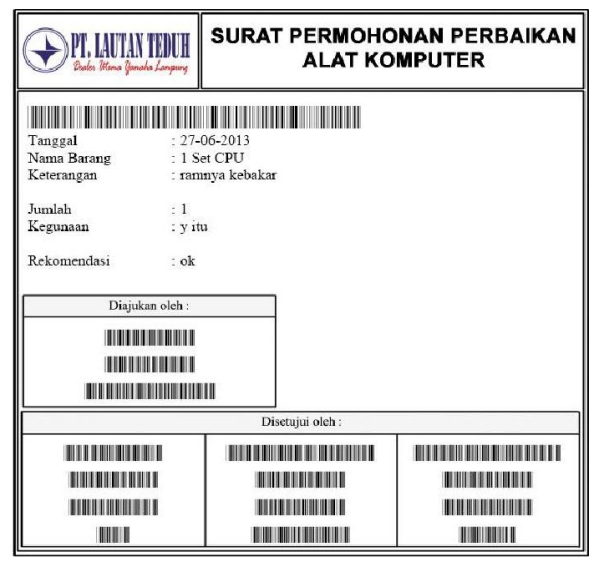

Gambar 29. Tampilan nota perbaikan

\section{B. Pembahasan}

Dalam menyelesaikan tugas akhir ini, peneliti mempelajari konsep dasar rancang bangun perangkat lunak khususnya pembuatan sistem informasi dari berbagai sumber di-internet dan beberapa buku. Hasil dari pemahaman konsep ini kemudian peneliti tuangkan dalam pembangun sistem informasi Persetujuan Perbaikan dan Pergantian Alat Komputer Berbasis Web dengan menggunakan metode RUP (Rational Unified Process) dan UML sebagai notasi pemodelannya.
Setelah berhasil membuat Sistem Informasi Persetujuan Perbaikan dan Pergantian alat komputer berbasis web, peneliti menuangkannya dalam sebuah tabel untuk melihat perbandingan sistem lama yang masih manual dengan sistem baru yang berbasis web.

Tabel 3. Perbandingan sistem manual dan sistem berbasis web

\begin{tabular}{|c|c|c|c|}
\hline No & Proses & Sistem Manual & Sistem berbasis nab \\
\hline 1 & $\begin{array}{l}\text { Kirim } \\
\text { Permohonan }\end{array}$ & $\begin{array}{l}\text { Dealer mengisi kartas } \\
\text { formulir permohonan, lalu } \\
\text { mengirimkan formulir ke } \\
\text { dealer utama melalui POS, } \\
\text { proses ini bisa memakan } \\
\text { waktu lebih dari } 2 \text { hari. }\end{array}$ & $\begin{array}{l}\text { Daaler cukup mangakses } \\
\text { halaman web sistem dan } \\
\text { mengis ifonm permohonan } \\
\text { yang ters edia, dengan cara ini } \\
\text { hanya membutuhkan waktu } \\
\text { tidak lebih dari } 5 \text { menit. }\end{array}$ \\
\hline 2 & $\begin{array}{l}\text { Cal } \\
\text { permohonan }\end{array}$ & $\begin{array}{l}\text { Dealer harus menghubungi } \\
\text { dealer utama melalui } \\
\text { telpon atau email untul } \\
\text { mengatahui permohonan } \\
\text { yang diajukan dis atujui } \\
\text { atau ditolak. Proses ini bisa } \\
\text { memakan walktu lebih dari } \\
5 \text { menit malalui telephon } \\
\text { dan email. }\end{array}$ & $\begin{array}{l}\text { Daaler culup mambulka } \\
\text { halaman web dan memilih } \\
\text { menu lihat permohonan, di } \\
\text { daftar permohonandapat } \\
\text { langsungterlihat permohonan } \\
\text { sudah diterima atau ditolak } \\
\text { atau masih dalam proses. } \\
\text { Dengan cara ini hanya } \\
\text { membutuhlan waktu tidak } \\
\text { lebih dari } 2 \text { menit. }\end{array}$ \\
\hline 3 & $\begin{array}{l}\text { Raspon dan } \\
\text { rekomendasi }\end{array}$ & $\begin{array}{l}\text { Raspon parmohonan } \\
\text { bergantungpada masing- } \\
\text { masing aktor yang } \\
\text { battanggungjawab. }\end{array}$ & $\begin{array}{l}\text { Raspon pamohonam juga } \\
\text { masih bergantungpada } \\
\text { masing-masingaktoryang } \\
\text { battnggungjawab. }\end{array}$ \\
\hline 4 & Inventarisasi & $\begin{array}{l}\text { Proses pencariandetail } \\
\text { informasi setiap alat } \\
\text { komputer masihmelalui } \\
\text { dokumen-dolumen. Prosas } \\
\text { membutuhkan waktulebih } \\
\text { dari } 30 \text { menit. }\end{array}$ & $\begin{array}{l}\text { Pencarian detail informasi } \\
\text { setiap alat komputer bisa } \\
\text { dilakulan denganmengaksas } \\
\text { databasa permohonan. Proses } \\
\text { pencarian data hanya } \\
\text { mambutuhlan walktu tidal. } \\
\text { lebih dari } 2 \text { menit. }\end{array}$ \\
\hline & & Total waktu $=2915$ menit & Total waltu = 9 menit \\
\hline
\end{tabular}

Dari tabel perbandingan yang penulis buat di atas, dapat terlihat perbedaan antara sistem lama yang masih menggunakan cara manual untuk melakukan permohonan perbaikan ataupun pergantian alat komputer. Dari tabel juga terlihat keunggulan yang dimiliki oleh sistem baru yang berbasis web, yaitu waktu yang dibutuhkan untuk melakukan sebuah permohonan jauh lebih cepat, dengan perbandingan sistem manual membutuhkan waktu lebih dari 2 hari dan dengan sistem informasi berbasis web hanya membutuhkan waktu tidak lebih dari 9 menit. Dan juga kemudahan untuk mengetahui detail 
informasi setiap alat komputer yang tersebar disemua dealer. Namun dalam hal proses respon dan rekomendasi perbandingan sistem lama dan sistem baru yang berbasis web, masih sangat bergantung pada masing-masing aktor yang bertanggung jawab.

\section{SIMPULAN DAN SARAN}

\section{A. Simpulan}

Dari hasil dan pembahasan pada penelitian ini, dapat diambil beberapa kesimpulan:

1. Telah berhasil dibuat sistem informasi persetujuan perbaikan dan pergantian alat komputer berbasis web menggunakan metode Rational Unified Process dan menggunakan UML (unified modelling language) sebagai notasi pemodelannya.

2. Telah terbuka peluang peningkatan kinerja dalam aspek percepatan proses pengajuan permohonan perbaikan atau pergantian alat komputer.

3. Dari hasil uji coba Sistem Informasi persetujuan Perbaikan dan Pergantian alat komputer berbasis web, permohonan persetujuan perbaikan dan pergantian alat komputer telah dapat dikirimkan melalui sistem tanpa harus dilakukan pengiriman secara manual menggunakan kertas.

\section{B. Saran}

Dalam perancangan dan pembangunan sistem penulis menyadari masih terdapat kekurangan pada sistem yang dibangun. Oleh karena itu penulis memberikan saran yang dapat digunakan untuk mengembangkan sistem di kemudian hari.

1. Dapat dilakukan pengembangan Application Programming Interface Sistem Informasi Persetujuan Perbaikan dan Pergantian alat komputer berbasis web untuk perangkat mobile.

2. Sistem dapat dibuatkan suatu notifikasi atau peringatan yang bisa berupa email ataupun sms untuk setiap aktor yang terlibat, sehingga tidak harus membuka halaman web untuk melihat permohonan.

3. Proses penelitian dapat dilanjutkan sampai tahapan online untuk mengoreksi fungsi respon setiap aktor.

\section{DAFTAR PUSTAKA}

[1] Kadir, Abdul, Pengenalan Sistem Informasi, Andi Offset, Yogyakarta. 2003

[2] Rosa, A.S, dan M Shalahuddin, Modul Pembelajaran Rekayasa Perangkat Lunak (Terstruktur dan Berorientasi Objek), Modula, Jakarta. 2011

[3] http://www.uml-diagrams.org/

[4] Firdaus, 7 Jam Belajar Interaktif PHP \& MySQl dengan Dreamweaver, Maxikom, Palembang. 2007 